\title{
Spectrum and antibiogram of bacteria isolated from patients presenting with infected wounds in a Tertiary Hospital, northern Tanzania
}

\author{
Nancy A. Kassam¹', Damian J. Damian ${ }^{1,2 *}$, Debora Kajeguka' ${ }^{1}$, Balthazar Nyombi ${ }^{1,2}$ and Gibson S. Kibiki²,3
}

\begin{abstract}
Objective: This study aimed to determine the spectrum and antibiogram of the isolated bacteria from patients presenting with infected wounds at Kilimanjaro Christian Medical Centre in northern Tanzania.

Results: Bacterial growth was observed in the vast majority of wound swabs (91.4\%). Most of the bacteria isolated (62.3\%) were Gram-negative rods. Staphylococcus aureus was the most common isolated organism (16\%) followed by other Coliforms and Enterococcus spp. (12.5\% each). Enterococcus spp. (36.4\%) was the most common isolated bacteria in diabetic wounds whereas $S$. aureus was the most common isolated bacteria from the wounds caused by trauma (40.0\%) and surgical site infection (20.6\%). Resistance was high to most common antibiotics used in the hospital.
\end{abstract}

Keywords: Wound infection, Drug resistance pattern, ESBL, Antibiogram, Surgical site infection, Diabetic wounds, Trauma wounds

\section{Introduction}

Bacterial infections of wounds are among the leading causes of morbidity and mortality throughout the world and are regarded as one of the most common nosocomial infections. Wound infections have been reported to vary between 3 and 11\% in developed countries and estimated to be as high as $40 \%$ in developing countries [1-3]. Wound infections increase with the degree of wound contamination, and it is estimated that $50 \%$ of wounds contaminated by bacteria become clinically infected [4].

Drug resistance impinges on the quality of patient care through its associated mortality, morbidity and significant economic consequences [5]. In hospital practice, $30-50 \%$ of antibiotics are prescribed for surgical prophylaxis and $30-90 \%$ of these prophylaxes are inappropriate [6]. Inappropriate use of antibiotics increases selection pressure favouring the emergence of pathogenic drugresistant bacteria which makes the choice of empirical antimicrobial agents more complicated $[7,8]$.

\footnotetext{
*Correspondence: d_jeremy5@yahoo.com

${ }^{1}$ Kilimanjaro Christian Medical University College (KCMUCo), P.O.

Box 2240, Moshi, Tanzania

Full list of author information is available at the end of the article
}

Extended spectrum beta-lactamase (ESBL) producing organisms are another type of common bacteria resistant to antibiotics. ESBL producing Gram-negative rods (GNRs) have spread all over the world [8,9]. The prevalence of ESBL producing GNR varies across the world from 50 to $80 \%[8,10,11]$. About $33 \%$ of infections by ESBL producers are deadly. In Tanzania, the death rate due to ESBL producing GNR is as high as $13.9 \%$ [12].

Comparing to Gram-negative, Gram-positives bacteria have been reported to be less prevalent causing wound infections [8, 11, 13-15]. Staphylococcus aureus (S. aureus) has been reported to be the most common isolated bacteria from different wound types. Pseudomonas aeruginosa are commonly isolated in infected wounds following surgeries and burns whereas Enterococcus species and Enterobacteriaceae are commonly isolated from wounds in immune-compromised patients and abdominal surgeries $[4,8,16-18]$.

The majority of the isolates from infected wounds are known to be resistant to ampicillin and amoxicillin. Large numbers of $S$. aureus are methicillin-resistant $S$. aureus (MRSA) and most bacteria isolated are sensitive to quinolones, aminoglycosides and monobactam $[10,11$, 19-21]. 
Infection in a wound delays healing, prolongs hospital stay, increases trauma, poses risk for disarticulation and amputation, increases need for medical care and increases treatment costs [22]. This makes infection of wounds a matter of concern and makes it necessary to study the causative agents of these infections and their antibiogram.

\section{Main text}

Characteristics of participants and enrolment procedures

Patients with Surgical Sites Infections (SSI), infected diabetic wounds, infected wounds due to trauma, and patients with other infected wounds admitted in surgical ward at Kilimanjaro Christian Medical Centre (KCMC) from July 2013 to June 2014 were included in this study. Prior to enrolment in the study, patients were examined by a physician for a suspected or actual wound sepsis using the following criteria; 'cellulitis', 'maladour', 'pain', 'delayed healing, 'deterioration in the wound' or 'wound breakdown' and 'increase in exudate volume'. Patients presenting with at least three of these clinical signs were enrolled in the study. Chronic wound was differentiated from acute wound if it failed to heal within 4 weeks and showed no sign of improvement within 8 weeks.

\section{Data collection}

\section{Pus swabs collection and culture}

Wound swabs were collected from patients with infected diabetic wounds, surgical sites, trauma and other wounds by the research nurse. To avoid contaminating the swab with skin flora, pus or necrotic tissue, the wound was thoroughly cleansed with 60-120 mL sterile normal saline prior to taking the sample. Sterile gauze was used to remove excess saline from the wound surface and the pus swabs were collected using sterile swab by swabbing at the middle of the wound. When there were two or more wounds in the same location, separate swabs were used for each wound. A swab moistened with sterile normal saline was rolled deep in the wounds and inserted immediately into a tube containing Stuart's transport media for preservation of microbes and then transported to the laboratory $[8,16]$. Pus swabs were streaked on Blood Agar (BA) and MacConkey Agar (MCA) plates and incubated aerobically for $18-24 \mathrm{~h}$ at $37^{\circ} \mathrm{C}$. They were then observed for bacterial growth. Plates with no growth and with growth were re-incubated for another 18-48 h for isolation of bacteria that require extended incubation (slow growers) $[8,16,17]$.

\section{Identification of bacterial pathogens}

Standard techniques were used for identification of pathogenic bacteria isolated in pure cultures. Characteristic morphological appearances of colonies on media, Gram stains and standard biochemical tests including catalase, coagulase, oxidase, Voges Proskauer, hydrogen sulphide production, urease, methyl red, indole, citrate, CAMP test and sugar utilisation were used to characterise bacteria and identify them [17].

\section{Antibiotics susceptibility testing}

Drug susceptibility tests were performed using the Kirby-Bauer disk diffusion method according to Clinical and Laboratory Standards Institute (CLSI) guidelines. A sterile swab was dipped into the suspension of the isolate in normal saline, squeezed free from excess fluid against the side of tube and spread over the Mueller-Hinton agar plate. The density of suspension to be inoculated was determined by comparison with the optical density of McFarland 0.5 Barium sulfate solution. Sensitivity discs of appropriate antibiotics were placed onto the media and incubated at $37{ }^{\circ} \mathrm{C}$ for $16-18 \mathrm{~h}$ except for coagulasenegative staphylococci which was incubated for $24 \mathrm{~h}$ and methicillin-resistant staphylococci at $35^{\circ} \mathrm{C}$ [23]. Zones of inhibition were read and, incubation and resistance rates to respective antibiotics were determined.

\section{ESBL production screening}

ESBLs production was tested by the disc diffusion method on Mueller-Hinton Agar according to the CLSI guidelines and confirmed by the double disc approximation method [23].

\section{Statistical analysis}

Clinical, demographic and laboratory data were entered and linked for each patient using Statistical Package for Social Science software version 20 (IBM Corp, Chicago IL). Thereafter, data were cleaned and analysed using Stata software (Version 13, StataCorp, College Station, Texas). Numeric variables were summarised using measures of central tendency with their respective measures of dispersion while frequency and percentages were used to summarise categorical data.

\section{Results \\ General characteristics of the study participants}

In total, 93 patients diagnosed with infected wounds were enrolled in this study. Male patients numbered 63 (67.7\%). The median (range) age at recruitment was $45(1-80)$ years. Most of participants, i.e. $65(71.4 \%)$ had acute wounds. The majority of patients, i.e. $82(90.1 \%)$ indicated to have used antibiotics either as a prophylaxis or treatment previously. Additional file 1: Table S1 shows these results.

\section{Bacteria isolated}

A total of 93 wound swabs from 93 patients were cultured and 146 bacteria were isolated. Of them $91.4 \%$ had bacterial growth. Gram stains of pure cultures showed 
$91(62.3 \%)$ of the isolates were gram-negative rods. A total of 144 pathogenic bacteria were isolated from 83 cultures. Staphylococcus aureus was the most common isolate $(16.0 \%)$ followed by other Coliforms and Enterococcus spp. (12.5\% each). Figure 1 shows these results.

More than one-third of the wound infections were caused by single isolate, i.e. 38 (44.7\%). According to the type of wounds, Staphylococcus aureus was the most isolated bacteria in acute wounds (29.1\%) followed by Pseudomonas aeruginosa (18.2\%) and other Coliforms (23\%). Whereas in chronic wounds, Proteus mirabilis (26.9\%) followed by Enterococcus species and Escherichia coli (23.1\%) were the most common isolated bacteria. Additional file 2: Table S2 and Additional file 3: Figure S1 depict these results.

\section{Antibiogram of the isolated bacteria}

Staphylococcus aureus showed high resistance to amoxicillin (61.9\%). Most Gram-negative rods isolated were very resistant to amoxicillin-clavulanate and cotrimoxazole (66.7-100\%) respectively. Tables 1 and 2 show these findings.

\section{ESBL producing Gram-negative rods}

The 44 Gram-negative rods isolated, including Klebsiella pneumoniae, Escherichia coli and Proteus species, were phenotypically tested for ESBL production. Half (50\%) of these isolates were ESBL producers. All ESBL-producing
Table 1 Drug resistance patterns of Gram positive isolates

\begin{tabular}{llll}
\hline Antibiotics & \multicolumn{2}{l}{ Gram positive isolate $(\%)$} \\
\cline { 2 - 4 } & $\begin{array}{l}\text { S. aureus } \\
(\boldsymbol{n}=\mathbf{2 3})\end{array}$ & CNS $(\boldsymbol{n}=7)$ & $\begin{array}{l}\text { Enterococcus spp. } \\
(\boldsymbol{n}=\mathbf{1 8})\end{array}$ \\
\hline Amoxicillin & $61.9^{\mathrm{a}}$ & $33.3^{\mathrm{a}}$ & $35.7^{\mathrm{a}}$ \\
Amoxicillin-cla- & $\mathrm{NT}$ & 57.1 & 47.1 \\
vulanate & & $33.3^{\mathrm{a}}$ & $\mathrm{NT}$ \\
Ceftriaxone & 21.7 & $0.0^{\mathrm{a}}$ & $31.3^{\mathrm{a}}$ \\
Ciprofloxacin & 4.3 & 0.0 & $\mathrm{NT}$ \\
Gentamycin & 17.4 & 0.0 & $\mathrm{NT}$ \\
Clindamycin & $14.3^{\mathrm{a}}$ & 42.9 & $42.9^{\mathrm{a}}$ \\
Erythromycin & $45.0^{\mathrm{a}}$ & &
\end{tabular}

NT, not tested; CNS, Coagulase negative Staphylococcus

a Not all bacteria were tested against a particular drug

Gram-negative rods showed 100\% resistance rates to ceftriaxone, cefotaxime and cotrimoxazole. These bacteria showed resistance rates of $60-100 \%$ to amoxClav, ceftazidime and gentamycin. All ESBL producing GNR showed no resistance to amikacin.

\section{Discussion}

In this study, Gram-negative rods were the predominant and leading cause of wound infections. These findings are in line with those of previous studies in Asia and other African settings [8, 11, 13, 14]. This might be

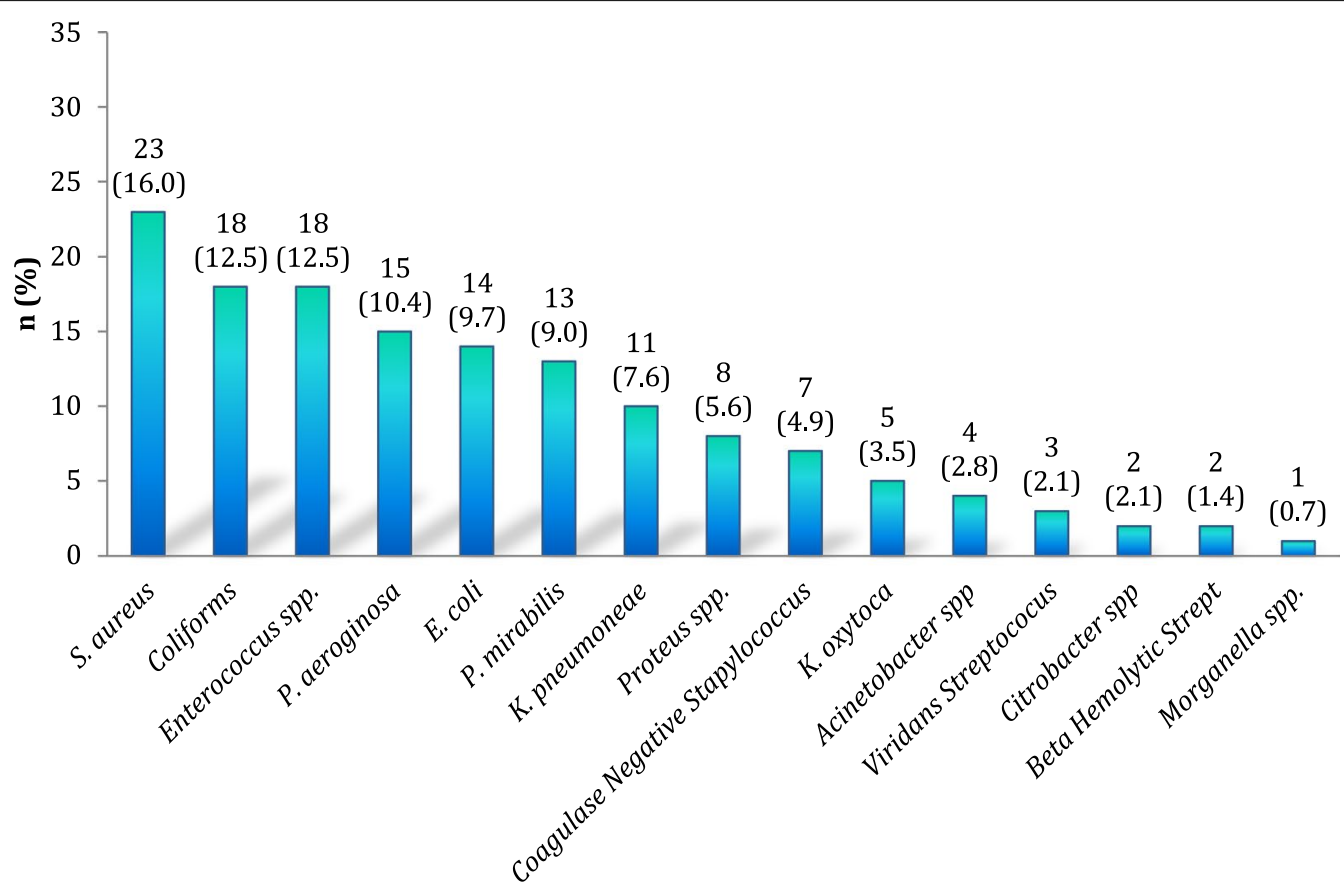

Fig. 1 Species of bacteria isolated

Bacteria isolated 
Table 2 Antibiotic resistance patterns for Gram negative rods isolated $(n=91)$

\begin{tabular}{|c|c|c|c|c|c|c|c|}
\hline \multirow[t]{2}{*}{ Antibiotics } & \multicolumn{7}{|c|}{ Gram negative rods isolated (\%) } \\
\hline & K. PN & K. OX & P. MR & P. SP & P. AE & E. CL & O. COL \\
\hline Amikacin & 0.00 & 0.00 & 0.00 & 0.00 & 0.00 & $0.00^{\mathrm{a}}$ & 4.0 \\
\hline Amoxicillin-clavulanate & 100.0 & 100.0 & 80.0 & $66.7^{\mathrm{a}}$ & 100.0 & 92.9 & 96.6 \\
\hline Ceftazidime & 70.0 & 20.0 & $12.5^{\mathrm{a}}$ & $33.3^{\mathrm{a}}$ & 25.0 & $18.2^{\mathrm{a}}$ & 72.0 \\
\hline Ceftriaxone & 70.0 & 20.0 & $37.5^{\mathrm{a}}$ & 22.2 & 21.4 & $38.5^{\mathrm{a}}$ & 64.0 \\
\hline Ciprofloxacin & 30.0 & 20.0 & 0.00 & $0.00^{\mathrm{a}}$ & 0.00 & 35.7 & 36.0 \\
\hline Cotrimoxazole & 100.0 & 80.0 & $66.7^{\mathrm{a}}$ & $77.8^{\mathrm{a}}$ & 92.9 & $84.6^{\mathrm{a}}$ & 84.0 \\
\hline Gentamycin & 50.0 & 60.0 & 40.0 & 22.2 & 28.5 & 50.0 & 52.0 \\
\hline Cefotaxime & $66.7^{\mathrm{a}}$ & $0.00^{\mathrm{a}}$ & $50.0^{\mathrm{a}}$ & $55.5^{\mathrm{a}}$ & 58.33 & $45.5^{\mathrm{a}}$ & $70.8^{\mathrm{a}}$ \\
\hline
\end{tabular}

Gram-negative rods isolated: K. PN, Klebsiella pneumoniae; K. OX, Klebsiella oxytoca; P. MR, Proteus mirabilis; P. SP, Proteus species; P. AE, Pseudomonas aeruginosa; E. CL, Escherichia coli; O. COL, Other Coliforms; Acinetobacter spp.; Citrobacter spp.; Morganella spp.

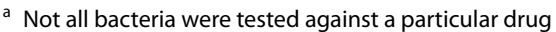

due to high resistances to antibiotics showed by Gramnegative bacteria compared to Gram-positive isolates, and therefore their persistence in infected wounds. Furthermore, chronic wounds were infected by multiple Gram-negative rods. The multiple bacterial infections in this case might be due to impaired immune responses associated with diabetes. These results are in accord with recent studies in Tanzania where polymicrobial wound infections were reported to be common in diabetic wounds [8, 24].

In general, Staphylococcus aureus was the most common bacteria isolated in this study. This is a finding consistent with most studies done across the world [10, 17, 21]. S. aureus are normal flora of the skin and anterior nares, therefore they can easily contaminate wounds and cause infections. Moreover, S. aureus are known to have a vast number of virulence factors that increase their ability to cause infections when compared to other bacteria. Our findings are contrary to the study conducted in a similar setting where Pseudomonas aeruginosa was the common isolate in SSI. These variations could be attributed to several factors including the nature of the surgical site itself, the wound site, the type of prophylactic antibiotics used for infections prevention, the level of nursing care given and the measures taken to prevent nosocomial infections [8, 10].

Enterococcus was the most common bacteria isolated in diabetic wounds, perhaps due to their opportunistic pathogen behaviour since lowered immune responses are associated with diabetes. Other common isolates from IDFUs were Proteus and Klebsiella, which are known to be common isolates in chronic wounds. These bacteria had high rates of ESBL production and showed high multiple drug resistance (MDR) rates. Studies elsewhere have reported similar findings [13-15, 20, 24].
In this study, high drug resistance was observed for amoxicillin-clavulanate and cotrimoxazole. These antibiotics are relatively cheap and readily available. These, together with policies that do not restrict antibiotics accessibility to patients, might have caused the irrational overuse of these drugs which might have led to bacterial resistance. Cephalosporins were ineffective against most Gram-negative rods. This might be due to mutational emergence and the spread of ESBL-producing Gram-negative rods and the extensive use of these antibiotics in both treatment and prophylaxis. In this setting, good responses were seen for ciprofloxacin and amikacin. In our setting, the use of these antibiotics is highly restricted due to their adverse side effects. Ciprofloxacin has been recommended only in certain bacterial infections. Furthermore, amikacin is very expensive in our community and the majority of patients could not afford to use it. The different levels of resistance to cefotaxime and ceftriaxone are surprising, although this may be influenced by the fact that not all isolates were tested against all antibiotics. Other studies showed findings in accordance with these $[8,10,19]$.

\section{Limitation}

Despite being a commonly-used, non-invasive and costeffective method, swabs might provide a poor specimen as compared to needle aspiration or tissue biopsy if not collected appropriately. Improper specimen collection affects the results obtained, often by reflecting normal skin flora and colonizing organisms, making it difficult to decide which organisms are the true pathogens. However, our results are not likely to be affected by this since the wound was cleansed thoroughly prior to swab collection. Moreover, the small sample size did not allow us to conduct advanced statistical analyses which could have potentially strengthened this study. 


\section{Additional files}

Additional file 1: Table S1. Background characteristics of the study population.

Additional file 2: Table S2. Bacteria isolated in different types of wound infection.

Additional file 3: Figure S1. Bacteria isolated from acute and chronic wounds.

\section{Abbreviations}

BA: Blood Agar; CLSI: Clinical and Laboratory Standards Institute; ESBL: Extended spectrum beta-lactamase; GNRs: Gram-negative rods; IDFU: Infected Diabetic Foot Ulcer; KCMC: Kilimanjaro Christian Medical Centre; KCMUCo: Kilimanjaro Christian Medical University College; KCRI: Kilimanjaro Clinical Research Institute; MCA: MacConkey Agar; MDR: multiple drug resistance; MRSA: methicillin resistant Staphylococcus aureus; SSI: surgical site infection.

\section{Authors' contributions}

NAK designed the study. NAK and DJD developed the data collection instruments. NAK, DJD, DK, BN, and GSK participated in data collection and were involved in producing the first draft of the manuscript. NAK and DJD analysed the data and interpreted the results. NAK, DJD, DK, BN, and GSK contributed to the final version of the manuscript. All authors read and approved the final manuscript.

\section{Author details}

${ }^{1}$ Kilimanjaro Christian Medical University College (KCMUCo), P.O. Box 2240

Moshi, Tanzania. ${ }^{2}$ Kilimanjaro Christian Medical Centre (KCMC), P.O. Box 3010, Moshi, Tanzania. ${ }^{3}$ Kilimanjaro Clinical Research Institute (KCRI), Moshi, Tanzania.

\section{Acknowledgements}

The authors thank the management of KCMC hospital and heads of respective departments for permission and support to conduct the study. Furthermore, we are extending our gratitude to the study nurses and patients who agreed to participate in the study.

\section{Competing interests}

The authors declare that they have no competing interests.

\section{Availability of data and materials}

The datasets analysed during the current study are not publicly available due to ongoing further analyses but are available from the corresponding author on reasonable request.

\section{Consent for publication}

Not applicable.

\section{Ethics approval and consent to participate}

Ethical approval to conduct this study was obtained from Kilimanjaro Christian Medical University College Ethical Committee-Institute Research Board. Permission to conduct this study was obtained from the executive director at KCMC, the head of clinical laboratory and respective clinical departments. Potential study participants provided written fully informed consent and assent for those below 18 years. In addition, written parental consent was obtained for the under age ( $<18$ years) study participants. Patients' hospital identification numbers were used instead of names for confidentiality purposes. Laboratory results were communicated back to the physicians for patient management.

\section{Funding}

None.

\section{Publisher's Note}

Springer Nature remains neutral with regard to jurisdictional claims in published maps and institutional affiliations.
Received: 17 October 2017 Accepted: 13 December 2017

Published online: 20 December 2017

\section{References}

1. Mayon-White RT, Ducel G, Kereselidze T, Tikomirov E. An international survey of the prevalence of hospital-acquired infection. J Hosp Infect. 1988;11:43-8.

2. Tikhomirov E. WHO programme for the control of hospital infections. Chemioterapia. 1987;6:148-51.

3. Ducel G, Fabry J, Nicolle L. Prevention of hospital-acquired infections. 2nd ed. Geneva: World Health Organization; 2002.

4. Balows A, Truper H, Dvorkin M, Harder W, Schleifer K. The prokaryotes. A handbook on the biology of bacteria: proteobacteria: gamma subclass. 2nd ed. New York: Springer; 1991. https://doi.org/10.1007/0-387-30745-1.

5. Kunin CM. Resistance to antimicrobial drugs - a worldwide calamity. Ann Intern Med. 1993;118:557-61.

6. MunckhofW. Antibiotics for surgical prophylaxis. Aust Prescr. 2005;28:3840. https://doi.org/10.18773/austprescr.2005.030.

7. Al-Momany NH, Al-Bakri AG, Makahleh ZM, Wazaify MMB. Adherence to international antimicrobial prophylaxis guidelines in cardiac surgery: a Jordanian study demonstrates need for quality improvement. J Manag Care Pharm. 2009;15:262-71. https://doi.org/10.18553/ jmcp.2009.15.3.262

8. Manyahi J. Bacteriological spectrum of post operative wound infections and their antibiogram in a Tertiary Hospital, Dar Es Salaam, Tanzania. Master thesis in Medicine (Microbiology and Immunology). Muhimbili University of Health and Allied Sciences; 2012

9. Grundmann H, Aires-de-Sousa M, Boyce J, Tiemersma E. Emergence and resurgence of meticillin-resistant Staphylococcus aureus as a publichealth threat. Lancet (London, England). 2006;368:874-85. https://doi. org/10.1016/s0140-6736(06)68853-3.

10. Shriyan A, Sheetal R, Nayak N. Arobic micro-organism in post-oprative wound infection and their antimicrobial susceptibility patterns. J Clin Diagn Res. 2010;3:2208-16.

11. Etok CA, Edem EN, Ochang E. Aetiology and antimicrobial studies of surgical wound infections in University of Uyo Teaching Hospital (UUTH) Uyo, Akwa Ibom State, Nigeria. Niger Open Access Sci Rep. 2012;1:1-5. https://doi.org/10.4172/scientificreports.

12. ReAct. A fact sheet from ReAct-action on antibiotic resistance. Uppsala; 2012.

13. Osariemen IJ, Olowu SS, Adevbo E, Omon EE, Victoria O, Imuetinyan EJ, et al. Aerobic bacteria associated with diabetic wounds in patients attending clinic in a rural community in Nigeria. Glob Res J Microbiol. 2013:3:8-12.

14. Banashankari GS, Rudresh HK, Harsha AH. Prevalence of Gram negative bacteria in diabetic foot-a clinico-microbiological study. Al Ameen J Med Sci. 2012;5:224-32

15. Raja NS. Microbiology of diabetic foot infections in a teaching hospital in Malaysia: a retrospective study of 194 cases. J Microbiol Immunol Infect. 2007:40:39-44.

16. Mohammed A, Adeshina G, Ibrahim YK. Incidence and antibiotic susceptibility pattern of bacterial isolates from wound infections in a tertiary hospital in Nigeria. Trop J Pharm Res. 2013;12(4):617-21.

17. Taiwo S, Okesina A, Onile B. In vitro antimicrobial susceptibility pattern of bacteria isolated from infected wounds at the University of Illorine teaching Hospital. Afr J Exp Exp Microbiol. 2002;3:13-6.

18. National Nosocomial Infections Surveillance. National Nosocomial Infections Surveillance (NNIS) system report, data summary from January 1992-June 2001. Am J Infect Control. 2001;29:470-85. https://doi. org/10.1067/mic.2001.119952.

19. Sule A, Thianni L, Sule-Odu O, Olusanya O. Bacterial pathogens associated with infected wounds in Ogun State University Teaching Hospital, Sagamu, Nigeria. Afr J Clin Exp Microbiol. 2002;3:13-6.

20. Orji F, Nwachuku N, Udora E. Original article bacteriological evaluation of diabetic ulcers in Nigeria. Afr J Diabetes Med. 2009;19:19-21.

21. Ahmed MI. Prevalence of nosocomial wound infection among postoperative patients and antibiotics patterns at teaching hospital in Sudan. N Am J Med Sci. 2012:4:29-34. https://doi.org/10.4103/1947-2714.92900. 
22. Emori TG, Gaynes RP. An overview of nosocomial infections, including the role of the microbiology laboratory. Clin Microbiol Rev. 1993;6:428-42.

23. CLSI. Performance standards for antimicrobial susceptibility testing; twenty-fifth informational supplement. CLSI document M100-S25. 2015.
24. Chalya PL, Mabula JB, Dass RM, Kabangila R, Jaka H, McHembe MD, et al. Surgical management of diabetic foot ulcers: a Tanzanian university teaching hospital experience. BMC Res Notes. 2011;4:365. https://doi. org/10.1186/1756-0500-4-365.
Submit your next manuscript to BioMed Central and we will help you at every step:

- We accept pre-submission inquiries

- Our selector tool helps you to find the most relevant journal

- We provide round the clock customer support

- Convenient online submission

- Thorough peer review

- Inclusion in PubMed and all major indexing services

- Maximum visibility for your research

Submit your manuscript at www.biomedcentral.com/submit
() Biomed Central 